\title{
Improving the workability of materials during the dieless drawing processes by multi-pass incremental deformation
}

\author{
Andrij Milenin $^{1}\left[\cdot\right.$ Tsuyoshi Furushima ${ }^{2} \cdot$ Peihua $^{D^{2}}{ }^{2} \cdot$ Valeriy Pidvysots'kyy ${ }^{3}$
}

Received: 6 February 2020 / Revised: 22 June 2020 / Accepted: 6 July 2020 / Published online: 12 July 2020

(c) The Author(s) 2020

\begin{abstract}
The paper explores the new method of improving the workability of materials in the dieless drawing processes. The proposed method is based on the implementation of a multi-pass incremental deformation. Moreover, in each pass, strain and strain rate sensitivity of flow stress should be positive and significant. An approach based on the finite element calculation of instability coefficient of plastic deformation and simultaneous modeling of material ductility were applied for prediction of the workability. Two dieless drawing processes have been investigated. The difference was related to the heating system-induction heating and laser heating. FE simulations and experimental tests for three materials, two magnesium alloys ( $\mathrm{MgCa} 0.8$ and $\mathrm{MgNi} 19)$ and pure copper were performed. It was shown that the most effective increase in workability by multi-pass deformation can be achieved using laser dieless drawing. This is possible due to the shorter heating area and, as a consequence, the larger strain rate, which leads to better stability of the deformation process.
\end{abstract}

Keywords Magnesium alloys $\cdot$ Dieless drawing $\cdot$ Ductility $\cdot$ Incremental deformation $\cdot$ Multi-pass deformation

\section{Introduction}

The process of dieless drawing is a stretching of the workpiece with its simultaneous local heating. Weiss and Kot [1] presented a first study of the wire production based on this method. Tiernan and Hillery [2] performed a theoretical analysis and FE simulation of a dieless drawing of steel wire. They confirmed that during the dieless drawing, there is a complex interdependence between the process parameters.

Andrij Milenin

milenin@agh.edu.pl

Tsuyoshi Furushima

tsuyoful@iis.u-tokyo.ac.jp

Peihua Du

dupeihua2255@163.com

Valeriy Pidvysots'kyy

vpidvysotskyy@imz.pl

1 Department of Applied Computer Science and Modelling, AGH University of Science and Technology, Mickiewicza 30, 30-059 Kraków, Poland

2 The University of Tokyo, Komaba 4-6-1, Meguro, Tokyo 153-8505, Japan

3 Institute for Ferrous Metallurgy, ul. K. Miarki, 12-14, 44-100 Gliwice, Poland
Currently, dieless drawing is widely used for the forming of various categories of products and materials. The application of this method for the production of tubes of the complex cross-section was investigated by Furushima et al. [3]. Tiernan et al. [4] showed an application of the dieless drawing for the deformation of bars. The heating source in the dieless drawing process is usually an electric furnace, an inductor, or a laser beam. In the latter case, the process is called laser dieless drawing and it was described by $\mathrm{Li}$ et al. [5]. The dieless drawing allows for elongation of the workpiece without using a deforming die and has several other advantages. For example, Supriadi et al. [6] showed that, by dieless drawing, it is possible to vary the stretching and cross-sectional shape of the workpiece along its length.

Sekiguchi et al. [7] noticed another important advantage of this method-the absence of friction. This simplifies the deformation of materials with low ductility. Extending this idea, Furushima and Manabe [8] applied a dieless drawing for the elongation of microtubes under superplastic conditions for $\mathrm{Zn}-\mathrm{Al}$ alloys and ceramic tubes (Furushima and Manabe [9]). Kustra et al. [10] demonstrated, that the dieless drawing process makes it possible to achieve significant workability of the workpiece in one pass (up to 60\%) for MgCa0.8 magnesium alloy. 
It is necessary to clarify exactly what is meant by workability. In this paper, workability is considered as the maximum final strain of the material to fracture achievable in the process of dieless drawing.

Milenin et al. [11] showed that usually the fracture of the material during dieless drawing is preceded by the instability of plastic deformation in the form of necking. This is caused by the fact that the dimensions of the final product are formed by free deformation of the material. Since in the process of dieless drawing the deformation state is close to a linear stretching, it can be assumed that the mechanisms of necking during the tensile test and the instability during dieless drawing are similar to each other. A general criterion of the instability of plastic deformation during the tensile test was proposed by Considère [12]. The basis of this criterion is that the instability of plastic deformation in the form of necking will not occur until the applied stress reaches the value of the slope of the stress-strain curve. However, this criterion cannot be used directly for prediction of instability during dieless drawing, because distributions of strain, strain rate, and temperature in the workpiece are very complicated. As an alternative to the use of this criterion, $\mathrm{He}$ et al. [13] used experimental studies to determine processing limit maps for the stable deformation during dieless drawing.

On the other hand, the increase of the stability of plastic deformation is difficult to achieve, since it is limited by the rheological properties of the material. Furushima and Manabe [8] analyzed the effect of strain-rate on deformation instability during dieless drawing. They showed that significant positive strain rate sensitivity of flow stress restrains the local unstable deformation. Additionally, Milenin [14] showed the relationship between strain sensitivity of flow stress and the occurrence of uneven product diameter. The method to improve the stability of deformation based on the multi-pass dieless drawing was proposed. In this process, deformation is carried out by cyclic repetition of the dieless drawing of one sample with small increments of elongation. The idea of the proposed method was that during each pass the processed material must be under conditions of intensive strain hardening. This is achieved using small deformations at each pass and restoring the mechanical properties of the material by recrystallization of the microstructure after each pass. Because multi-pass incremental deformation during dieless drawing can improve stability of deformation, it is logical to assume that this method can also increase the workability. Furushima and Manabe [15] used multi-pass dieless drawing for deformation of $\mathrm{Zn} 22 \% \mathrm{Al}$ alloy under superplastic conditions. However, the deformation parameters in each pass were determined experimentally, without regard to the stability criterion and the flow stress model of the material.

The beginning of the formation of necking during dieless drawing does not always lead to fracture but in this case, the uneven diameter of the finished product along the length can be observed. On the other hand, the fracture of some less ductile materials is possible before the formation of necking. Consequently, the control of instability alone is not enough to predict fracture and optimize the process to increase workability. To solve this problem, it is necessary to jointly use the models of ductility and instability of plastic deformation.

Thus, the main weakness of existing studies is the fact, that attempts to increase the workability during dieless drawing were carried out based on empirical data and without a quantitative coupled analysis of the stability of plastic deformation and ductility of a material. This significantly limits the applicability of these solutions to the problem of improving the workability. It especially concerns the processing of low-ductility materials (for example, magnesium alloys).

Also, a comparative analysis of the possibilities of improving workability in different multi-pass dieless drawing processes is of practical interest. A comparison of laser dieless drawing (LDD-laser dieless drawing) and dieless drawing with induction heating (DD-dieless drawing) is an example. To author's knowledge, there is no such analysis presented in the existing literature. Thus, the purpose of this study includes two aspects. The first is to develop a method for improvement of workability in the multi-pass processes of dieless drawing, based on analysis of plastic instability and exhaustion of ductility. The second is to analyze and compare the effectiveness of proposed multi-pass dieless drawing for two processes: one with induction heating (DD) and the second with laser heating (LDD).

The dieless drawing processes of tubes from various materials were selected as the object for the research.

\section{Materials models}

Two material models are needed for the FE simulation of the instability of plastic deformation and workability during dieless drawing: the model of flow stress and the model of ductility. Three materials were investigated: $\mathrm{MgCa} 0.8$ (Wt\%: Mg 99.2, Ca 0.8), MgNi19 (Wt\%: Mg 81, Ni 19), and pure copper (Wt\%: Cu 99.99). MgNi19 alloy is an example of extremely low ductile material (used by Crivello et al. [16] in chemical hydrogen accumulators). $\mathrm{MgCa} 0.8$ alloy (used in biomedical applications) has relatively good formability, which was demonstrated by Milenin et al. [17]. $\mathrm{Cu}$ is an example of high ductile material but with a very complicated stress-strain relationship during hot deformation, which was studied by Garcia et al. [18]. Thus, these alloys represent various groups of materials in terms of their formability in dieless drawing processes.

Experimental studies of the flow stress of these materials were performed based on compression tests on the GLEEBLE 
machine and Fig. 1 depicts selected flow stress curves. During experiments on the GLEEBLE machine, the accuracy of hardware temperature control was about $1{ }^{\circ} \mathrm{C}$. Cylindrical samples with an initial diameter of $8 \mathrm{~mm}$ and a height of $10 \mathrm{~mm}$ were used. The strain rate varied from 0.01 to $1 \mathrm{~s}^{-1}$. When the sample was deformed, the moment of its destruction was controlled. The onset of destruction was controlled by the criterion of a sharp decrease in the compression load. At this point, the deformation was automatically interrupted. Photos of some samples after destruction are shown in Fig. 1. In all cases, the same pattern of fracture was observed as shown in the photographs. Interruption of some curves in Fig. 1 meant the destruction of the sample. The deformation corresponding to the fracture was used to calibrate the ductility model. No destruction of copper samples was observed in plastometric tests. For this reason, a model of ductility for copper has not been developed.

In this study, the main method for improving workability is to increase the stability of deformation and inhibition of neck formation. The ductility model has a secondary value. For this reason, the following simplified ductility model was used. The analysis of ductile fracture was based on the accumulation of damage parameter $D$ :

$D=\int_{0}^{\varepsilon} \frac{\mathrm{d} \varepsilon}{\varepsilon_{\mathrm{f}}(t, \dot{\varepsilon})}$,

where $D \geq 1$ corresponds to fracture occurrence, $\varepsilon$ is the strain, $\varepsilon_{\mathrm{f}}(t, \dot{\varepsilon})$ is the critical strain when the fracture happens; $t$ is the temperature; $\dot{\varepsilon}$ is the strain rate.
Fig. 1 Flow stress curves used for simulation: a, b $\mathrm{MgNi} 19$; c, d $\mathrm{MgCa} 0.8 ; \mathbf{e}, \mathbf{f ~ C u}$
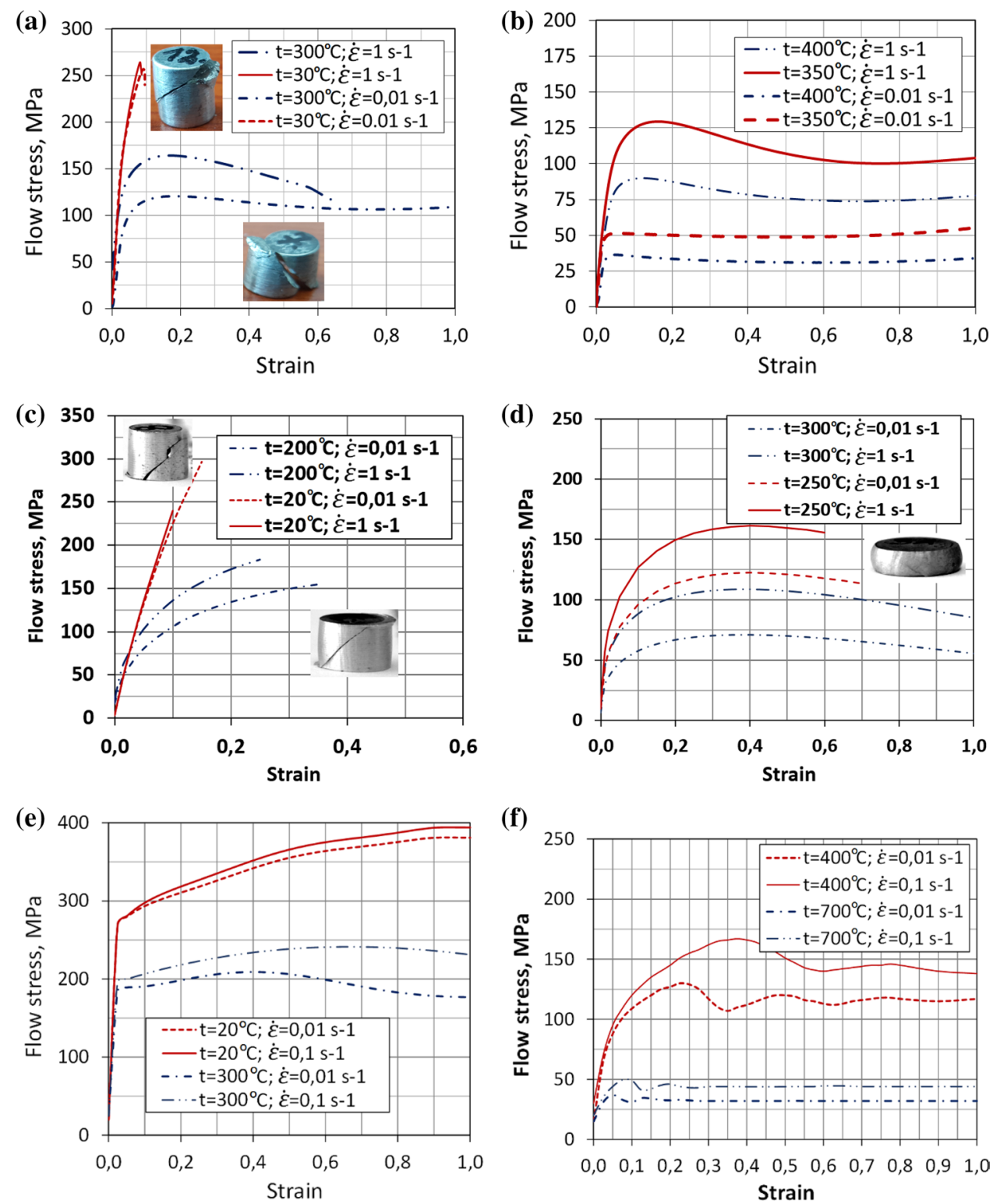

(f)
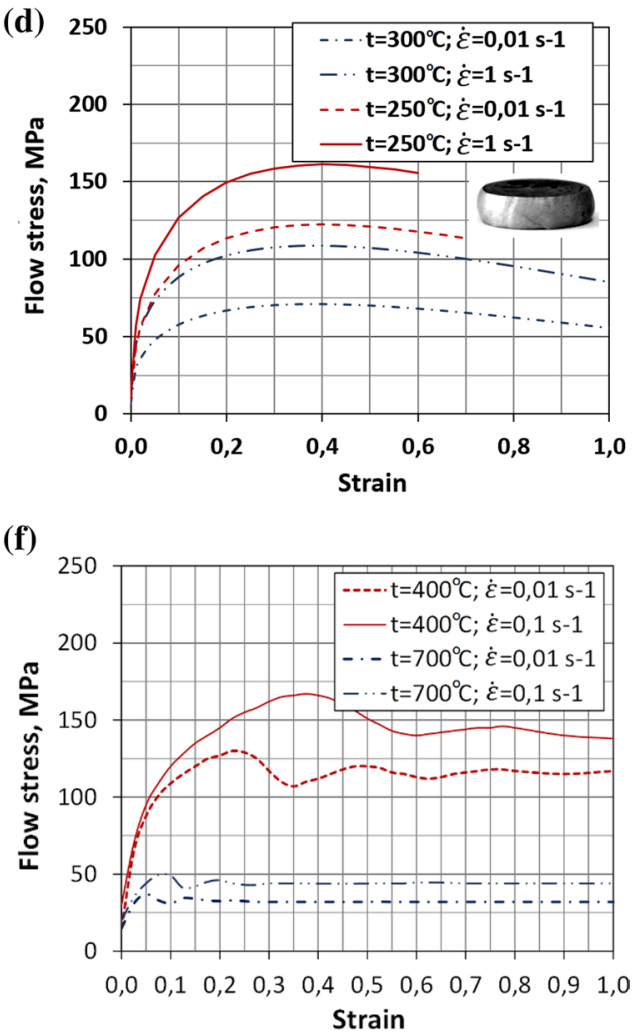
In the QForm FE software, the ductility model (1) was implemented in a form of numerical integration algorithm in LUA language. The critical strain $\varepsilon_{\mathrm{f}}(t, \dot{\varepsilon})$ associated with fracture was approximated as follows:

$\varepsilon_{\mathrm{f}}(t, \dot{\varepsilon})=d_{1} \exp \left(d_{2} t\right) \dot{\varepsilon}^{d_{3}}$.

This model was proposed by Milenin et al. [11] for the prediction of fracture during the dieless drawing of ZEK100 alloy. The absence of a triaxiality factor in Eq. (2) is explained by its insignificant change in the process of dieless drawing.

In Eq. (2), the empirical coefficients $d_{1}-d_{3}$ were determined using compression tests for two magnesium alloys, as follows:

- MgCa0.8 alloy: $d_{1}=0.136 ; d_{2}=0.00645 ; d_{3}=-1.22$;

- MgNi19 alloy: $d_{1}=0.0708 ; d_{2}=0.00708 ; d_{3}=-0.252$.

These coefficients were determined using the leastsquares method. As experimental data, the values of strains at which the samples were destroyed in plastometric tests and also the temperatures and strain rates corresponding to these tests were used.

Using only compression tests to calibrate the model (2) does not allow it to be used to analyze processes with a complex stress state. However, in the investigated case, the obtained model was used to determine the temperature below which the ductility of the material begins to decrease significantly and assess the effect of the strain rate on ductility. The last is practically important since laser dieless drawing leads to a higher strain rate in the material than conventional dieless drawing. A similar technique based on the use of only compression tests to assess formability was widely used in practice for the determination of processing maps (Rao et al. [19]) or dependence of formability on temperature (Doege et al. [20]).

A graphical interpretation of these results along with experimental data is shown in Fig. 2. The presented data show significantly higher ductility of the $\mathrm{MgCa} 0.8$ alloy compared to $\mathrm{MgNi19}$. For example, at a temperature of
$100{ }^{\circ} \mathrm{C}$, the critical strain of the $\mathrm{MgCa} 0.8$ alloy $(0.2$ in Fig. 2b) is almost twice the critical strain for the MgNi19 alloy ( 0.1 in Fig. 2 a). This requires a higher heating temperature for the alloy $\mathrm{MgNi} 19$ during dieless drawing.

Since copper is a more ductile material than magnesium alloys (in the compression tests, used to calibrate the flow stress model, copper did not fracture even at room temperature), the ductility model was not calibrated for this material. Evaluation of workability during the dieless drawing of copper was carried out only based on the analysis of the stability of plastic deformation.

The following parameter was used as a numerical characteristic of material hardening or softening:

$K=\frac{\mathrm{d} \sigma}{\mathrm{d} \varepsilon} \frac{1}{\sigma}$

where $\sigma$ is the flow stress.

The usage of this parameter to the quantitative characterization of the material softening to predict the localization of deformation during hot metal forming was proposed by Bylya et al. [21]. The analysis of the flow forming process with a complex stress state using a parameter $K$ was performed by Bylya et al. [22]. A special case of applying $K$ to the analysis of deformation instability is the instability criterion which was proposed by Considère [12] and used for the dieless drawing process by Wright and Wright [23]. For linear stretching, it was theoretically shown that $K<1$ corresponds to the condition when the process of plastic deformation becomes unstable. In other cases, for example, for the dieless drawing process, the critical value of $K$ should be chosen empirically. On the other hand, the start of unstable deformation does not mean immediate fracture, and for some time the process can take place under condition of unstable deformation. For example, Slomchak et al. [24] showed that the formation of a noticeable localization of deformation in the initial phase of rolling occurs at negative values of $K$.

In the process of dieless drawing, the cooling of the material after leaving the heating zone is a factor that further stabilizes the process. This leads to the fact that the initiated strain instability ceases by increasing the flow stress corresponding to cooling. Therefore, the dieless drawing process
Fig. 2 Critical strain associated with a fracture for $\mathrm{MgNi19}$ (a) and $\mathrm{MgCa} 0.8$ (b) alloys
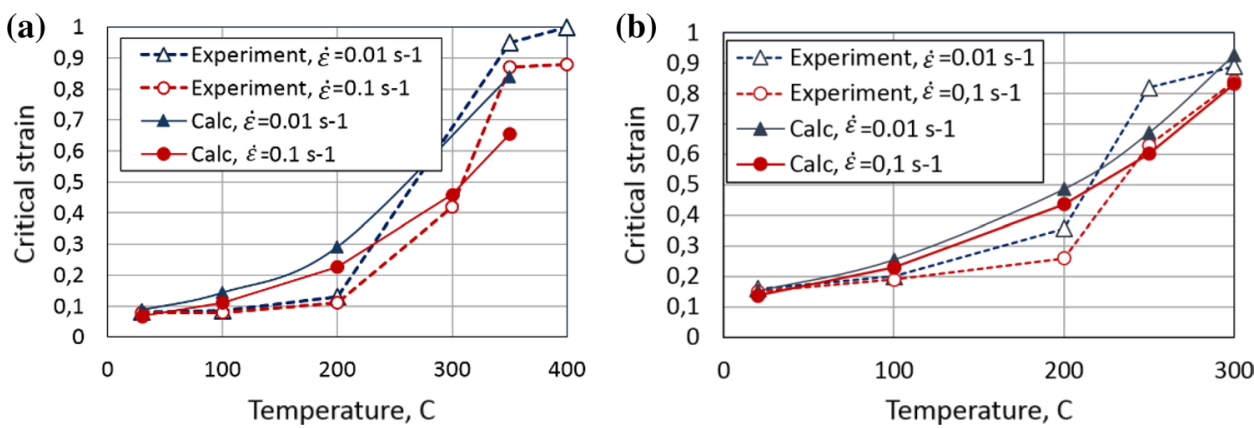
is usually more stable than simply stretching at a uniformly distributed temperature in the sample. For this reason, for a preliminary assessment of the stability of dieless drawing from stress-strain curves, the instability condition $K<0$ is adopted. This factor is fully taken into account in this work by the FEM modeling of dieless drawing.

A preliminary assessment of the conditions under which unstable deformation can begin can be done by applying Eq. (3) directly to the experimental data in Fig. 1. Figure 3 shows examples of the dependence of $K$ on temperature and strain.

If it is assumed that the maximum possible strain to failure during one pass of the dieless drawing should be about 0.8 , then from the curves in Fig. 2, it follows that the deformation temperature for the $\mathrm{MgCa} 0.8$ alloy should be $300{ }^{\circ} \mathrm{C}$, and for the MgNi19 alloy $350^{\circ} \mathrm{C}$. For this temperatures and strain rate $0.01 \mathrm{~s}^{-1}$ strain, which corresponded to condition $K=0$ was 0.4 for $\mathrm{MgCa} 08$ (Fig. 3a) and 0.15 for $\mathrm{MgNi} 19$ (Fig. 3b). These strains correspond to high strain hardening (positive slope of the stress curve relative to the strain axis in Fig. 1b, d) and considerable sensitivity of the stress to the strain rate (a large difference between the curves for different strain rates). Moreover, as follows from Fig. 3a, b a decrease in strain lead to a significant increase in $K$. However, a decrease in strain in one pass during the dieless drawing process leads to a decrease in the productivity of the process. Thus, it is necessary to find a compromise between increasing the stability of the deformation (high $K$ values) and the productivity of the process (large strains and lower $K$ values).

For copper, the temperature of dieless drawing was determined by an analysis of the stability of plastic deformation only. In this case, however, the choice is ambiguous, since in a range of temperature when strain hardening is significant $\left(20-400{ }^{\circ} \mathrm{C}\right)$, sensitivity to strain rate is very low. Stable and positive sensitivity of flow stress to strain rate appears for temperatures above $700{ }^{\circ} \mathrm{C}$. However, at these temperatures,
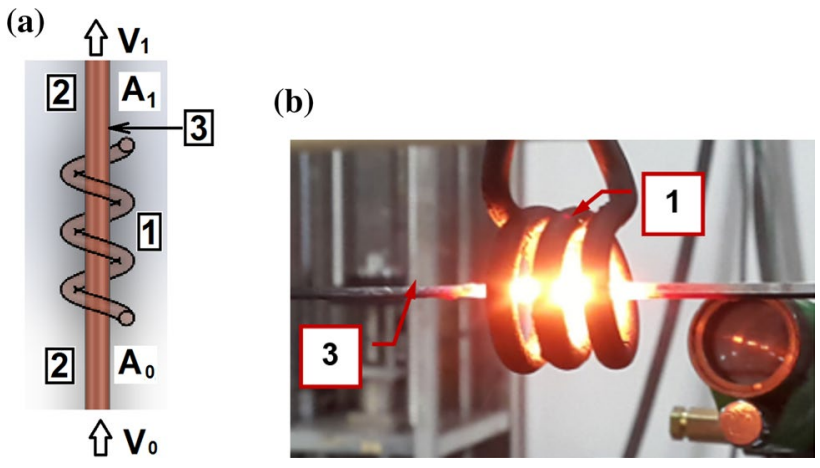

Fig. 4 Principle scheme of DD process (a) and example of installation (b): 1 - the heating device (inductor); 2 - the sample fixed in the equipment; 3 - the sample

the strain hardening is very small and not monotonic (the wave-like character of the curves in Figs. 1e, 3c). Thus, it could be assumed that copper will show a minimal increase in workability when using a multi-pass dieless drawing process instead of a single-pass process.

The above arguments are approximate since the stressed, deformed state and temperature distribution in the material during compressive tests deviated from the conditions of dieless drawing. For this reason, to confirm the assumptions made, it was necessary to perform FE calculations and experimental validation.

\section{Methods of dieless drawing}

\subsection{Experiment}

Two processes of dieless drawing (dieless drawing with induction heating, DD and laser dieless drawing, LDD) were considered. During DD (Fig. 4), the length of the heating zone (and the deformation zone) was $30 \mathrm{~mm}$ and temperature
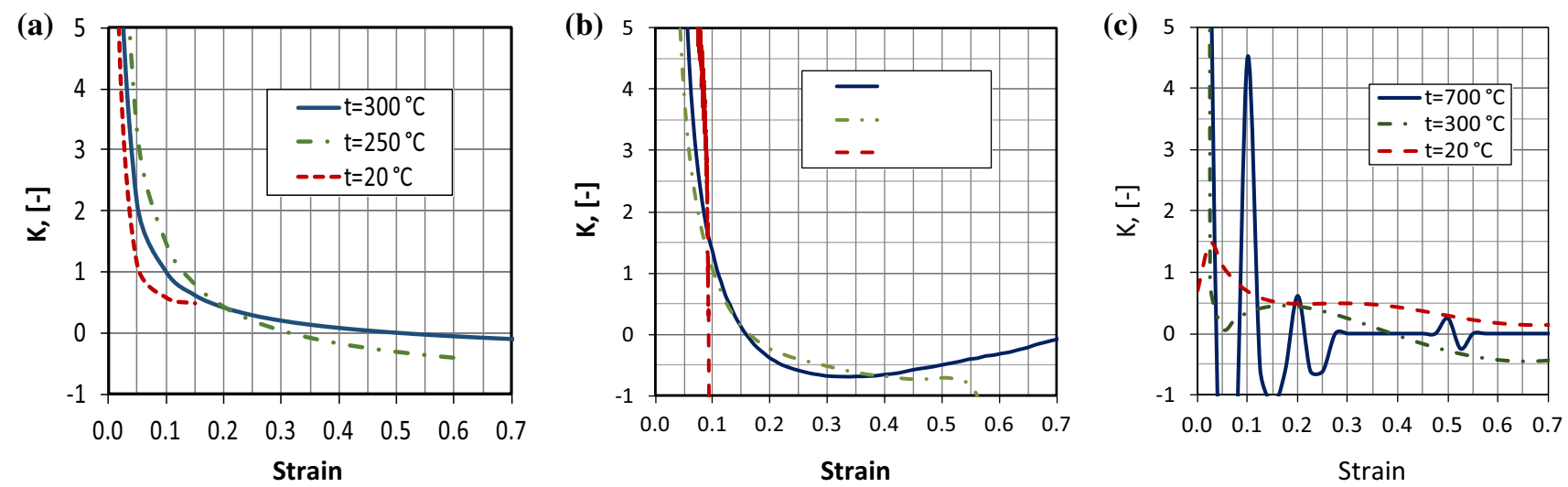

Fig. 3 Dependence of parameter $K$ on temperature and strain for strain rate $0.01 \mathrm{~s}^{-1}$ : a MgCa08; b MgNi19; $\mathbf{c} \mathrm{Cu}$ 
distribution was axisymmetric. During LDD (Fig. 5), the diameter of the laser beam (and the length of the heated zone) was $4 \mathrm{~mm}$. During LDD, the workpiece was rotated at a speed of $200 \mathrm{rpm}$ with the aim of symmetric heating. This allowed considering both tasks as axisymmetric.

The heating device in the installation is stationary and the workpiece moves relative to it as shown in the scheme (Fig. 6). The total initial length of the samples was about $500 \mathrm{~mm}$, the length of the ends of the sample with uneven deformation was about $50 \mathrm{~mm}$. The main controllable factors affecting the LDD and DD process are speeds of ends of the tube $V_{1}$ and $V_{0}$. The area reduction of the tube $R$ in the heated zone can be approximately determined from the volume constancy condition for $V_{1}>V_{0}$ :

$R=1-\frac{V_{0}}{V_{1}}$

In the multi-pass dieless drawing, deformation is carried out by cyclic repetition of the dieless drawing of one sample with small increments of elongation. Multi-pass dieless drawing differs in that the process depicted in Fig. 6 is repeated many times for one sample with small increments of elongation. In this case, the sample is not

(a)

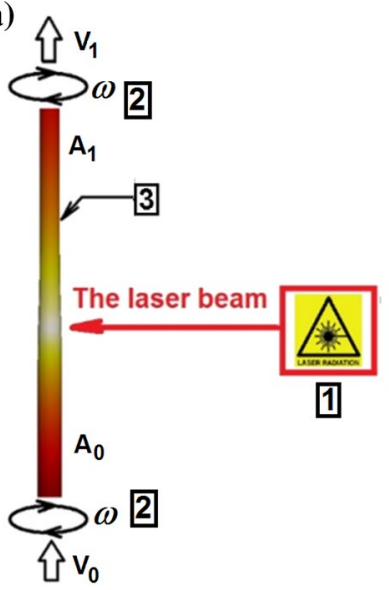

(b)

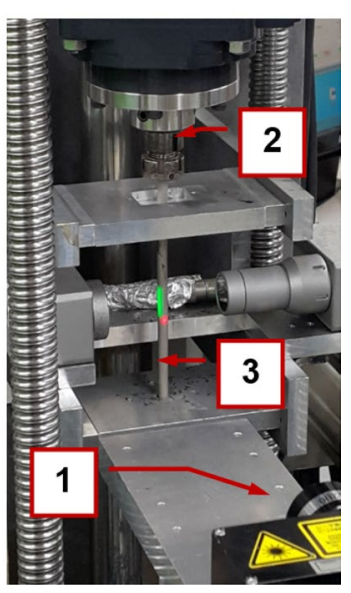

removed from the installation, which minimizes performance losses. At each pass, a very small elongation of the sample occurs. The magnitude of the elongation at each pass is an important additional parameter that must be determined when designing the process. As with the conventional process, two cases of the multi-pass dieless drawing were considered: dieless drawing with induction heating (MDD) and with laser heating (MLDD).

\subsection{FE simulation}

FE simulation was performed with the usage of QForm software. The theoretical foundations and examples of practical applications of the QForm program are described by Biba et al. [25]. A rigid plastic model of an incompressible material was chosen. Flow stress models for all materials were implemented in the QForm software in tabular form based on the data presented in Fig. 1. For all simulations (dieless drawing and tensile tests), the parameter $K$ was calculated in every time step by Eq. (3) in every node of the FE grid and it was implemented in the QForm software using a script in LUA language. Kinematic boundary conditions were set following the scheme in Fig. 6. At the ends of the tube, the velocities $V_{0}$ and $V_{1}$ were applied. The heating device is assumed to be motionless. The greatest difficulty was the specification of thermal boundary conditions for both induction and laser heating. To simplify this task, the temperature in the deformation zone was continuously monitored in the experiment using an IR camera. This allowed the use of a simplified method to determine the boundary conditions. The desired heat flux was chosen so that the maximum temperature in the deformation zone corresponded to the measurement results. The length of the heating zone corresponded to the length of the induction furnace for the DD process and the diameter of the laser spot for LDD.

Fig. 5 Principle scheme of LDD process (a) and example of installation (b): 1-the heating device (laser); 2 -the sample fixed in the equipment; 3 -the sample

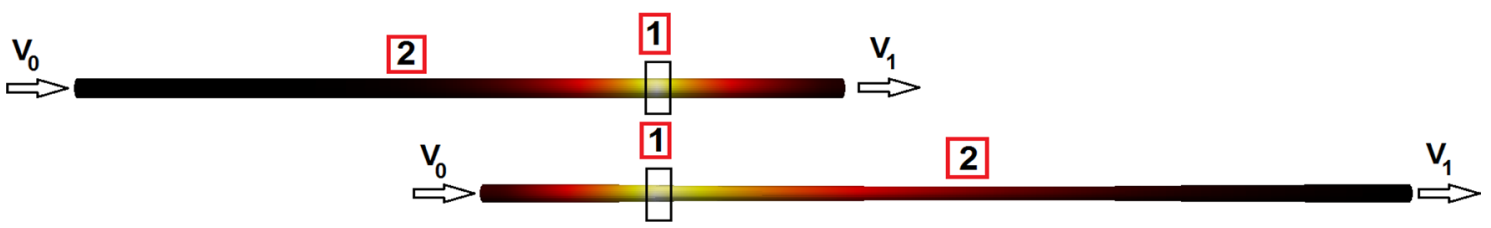

Fig. 6 Scheme of the initial (top) and final (down) position of the sample in dieless drawing setup during one pass of deformation: 1-heating device; 2-sample 


\section{Experimental tests}

\subsection{Experimental validation of the concept on the example of multi-stage stretching}

The idea of improving workability is illustrated by the example of stretching a $\mathrm{MgCa} 0.8$ alloy sample (Fig. 7) at a uniformly distributed temperature in it. Thus, the multi-pass dieless drawing process in this experiment was replaced by multi-stage stretching of the sample at a constant and uniformly distributed temperature. During stretching stage, $V_{0}$ and $V_{1}$ was $0 \mathrm{~mm} / \mathrm{s}$ and $1 \mathrm{~mm} / \mathrm{s}$, respectively (Fig. 8). During pause, $V_{0}=V_{1}=0 \mathrm{~mm} / \mathrm{s}$. The sample for stretching (in FE modeling, single-stage, and multi-stage experiments) was a rod with an initial diameter of $4 \mathrm{~mm}$ and a deformable length of $28 \mathrm{~mm}$. The samples had an initial stress concentrator (Fig. 7a) for simulation of possible heterogeneity of the diameter along the length of the workpiece. The entire sample was uniformly heated to a temperature of $300{ }^{\circ} \mathrm{C}$ and deformed at this temperature. The experiments were carried out on a Zwick250 machine using a furnace that uniformly heats the sample. The scheme of the experiment is shown in Fig. 8. The temperature fluctuations in the sample during the deformation did not exceed $1{ }^{\circ} \mathrm{C}$. When monotonically stretched at a speed of $1 \mathrm{~mm} / \mathrm{s}$ at a temperature of $300{ }^{\circ} \mathrm{C}$, the sample was destroyed at an elongation of $18.5 \mathrm{~mm}$ (variant 1). The simulation of this process showed that at the moment of fracture, the parameter $D$ is close to 1 (Fig. 7b). In the moment of fracture, the value of $K$ is below 0 (Fig. 7c). This experiment (variant 1 ) physically models a conventional single-pass dieless drawing process.

The next experiments (variants 2, 3, and 4) physically simulated the multi-pass dieless drawing. They differed

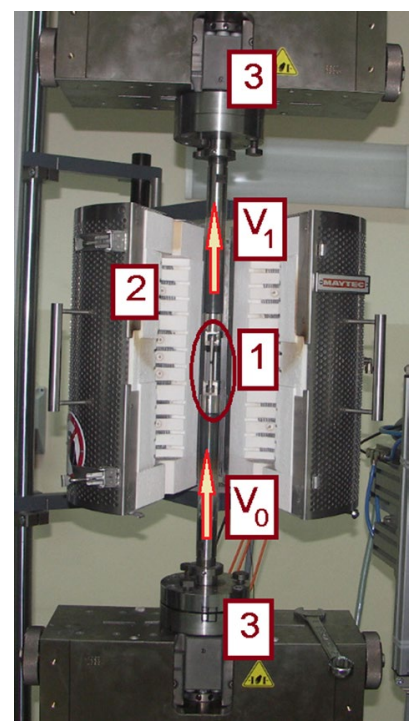

Fig. 8 The scheme of the experiment of the single-stage and multistage stretching of the sample: 1-sample; 2-furnace in the opening state; 3-deformation device Zwick 250

in that the sample was stretched in several stages with different increments of elongation and with pauses between the stages, during which the material recovered its properties. All other conditions (temperature, strain rate at the stage of deformation, the initial shape of the samples) were the same for all experiments in this series. Thus, the deformation scheme was the same as in the study of the one-stage process (Fig. 8); however, the stretching was not performed monotonously, but with specified elongation increments and pauses between them. During pauses, the position of the ends of the samples was fixed cinematically rigidly by setting the appropriate option in the software (a)

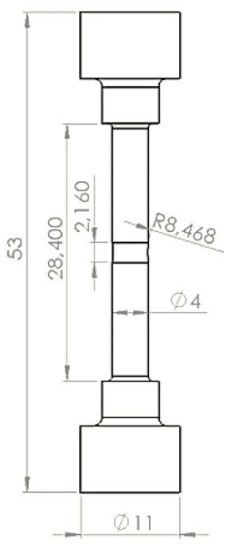

(b)

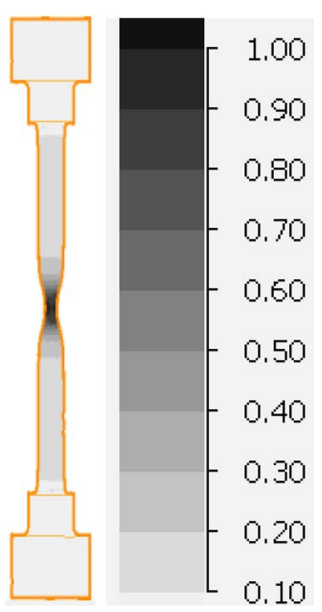

(c)

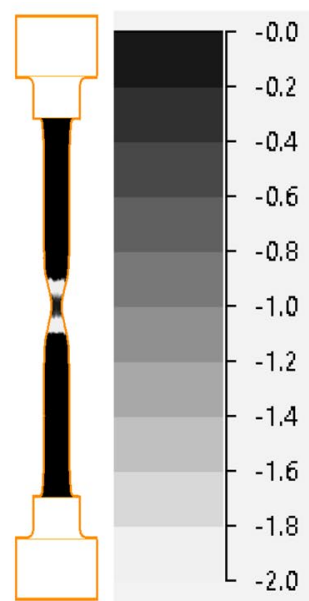

(d)

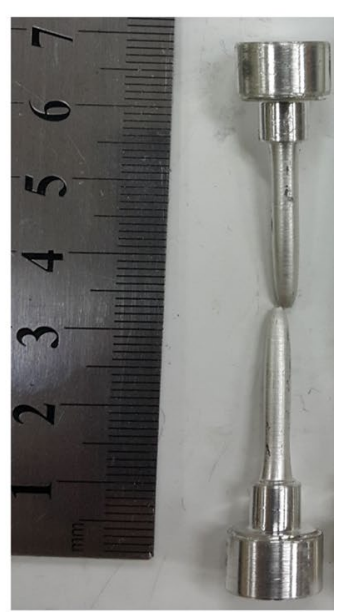

Fig. 7 Results of the monotonic stretch of the sample at a speed of $1 \mathrm{~mm} / \mathrm{s}$ at a temperature of $300{ }^{\circ} \mathrm{C}$ : a sample for stretching; b simulation of ductility parameter $D$ at the moment of fracture; $\mathbf{c}$ simulation of parameter $K$ at the moment of fracture; $\mathbf{d}$ sample after the fracture 
of the Zwick 250 machine. At the stage of active loading and during pauses, a change in load was recorded both over time and depending on the elongation of the sample. Using this method, the experimental load-time dependencies were obtained, which are presented in Fig. 9 for the first stage of deformation and pause. In Fig. 10, these data are shown for all stages of deformation of samples in the load-as elongation coordinates. In these figures, the curve for variant 1 is monotonic, since in this case the deformation is carried out without pauses. The curves for variants $2-4$ contain both stages of active loading and pauses, during which the relaxation of the load is recorded.

In these experiments, samples were deformed with increments of elongation in each stage equal $2 \mathrm{~mm}$ (variant 2), $1 \mathrm{~mm}$ (variant 3), and $0.5 \mathrm{~mm}$ (variant 4) and with a pause of $60 \mathrm{~s}$ between the stages. The strain rate at each stage of the

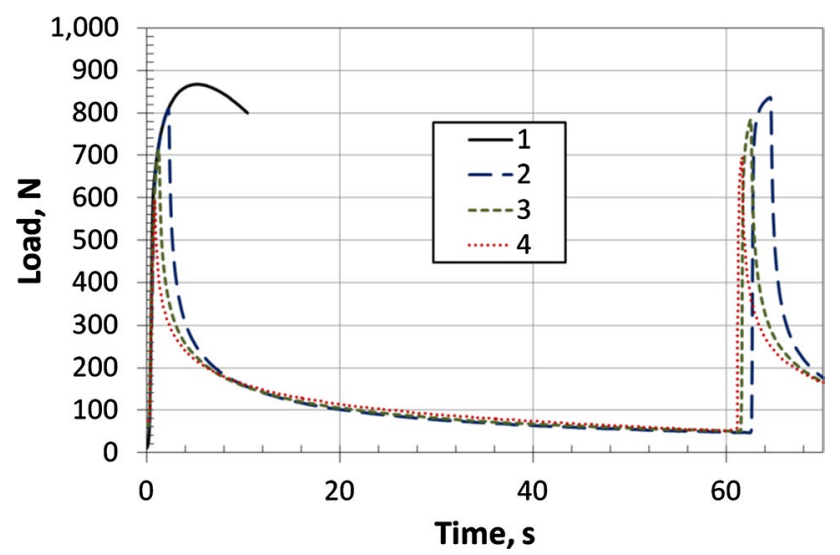

Fig. 9 Dependence of the load on time for the first and second stages of stretching for variants $1-4$ deformation was approximately $0.04 \mathrm{~s}^{-1}$, which is close to the values of strain rate characteristic of the dieless drawing process (excluding the final phase of deformation just before the fracture, at which the neck was formed). Average strain rate during stretching stage was calculated by the equation $\dot{\varepsilon}=\left(V_{1}-V_{0}\right) / L_{0}$ where $L_{0}$ is length of deformable part of the sample from Fig. 7a $(28 \mathrm{~mm})$. Obviously, this is approximate value, because the sample is continuously stretched.

A pause between the stages of deformation allows achieving two goals. The first and obvious one is the restoration of the ductility of the material. In our case, however, this goal is not the main one because if a neck begins to form during the drawing process, even highly ductile material will be destroyed. The second goal is to ensure that the stress-strain curve of the material after the pause is as close as possible to the stress-strain curve of the initial material. This will allow us to have a larger $K$ value at all steps of deformation. As a result, this will inhibit the development of the neck and subsequent fracture of the material.

During pauses, the recrystallization of the material was controlled by a method proposed by Karjalainen and Perttula [26], which is based on measuring the stress relaxation in the sample. To do this, the sample was not unloaded in pauses between deformations and stress relaxation was measured. This method of controlling recrystallization can be used in real dieless drawing processes since each installation usually contains a force measurement sensor.

The results of the load measurement showed that within $5-10 \mathrm{~s} 80 \%$ of the load relaxes, which indicates almost complete recrystallization of the material during this time (Fig. 9).

The change in the shape of load-elongation curves shown in Fig. 11 occurs as the fracture of the sample approaches,

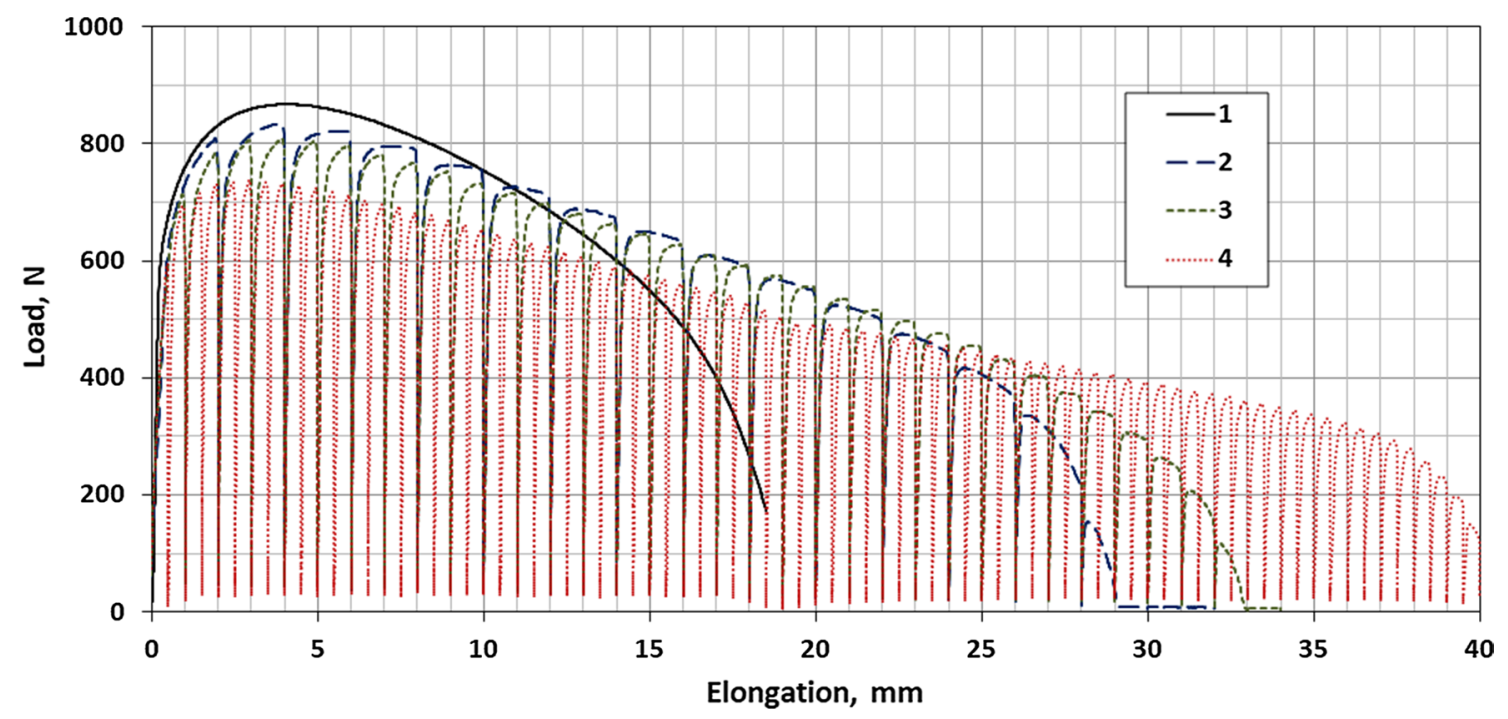

Fig. 10 Load-elongation curves for all tests of the multi-stage stretching (variants 1-4) 
(a)

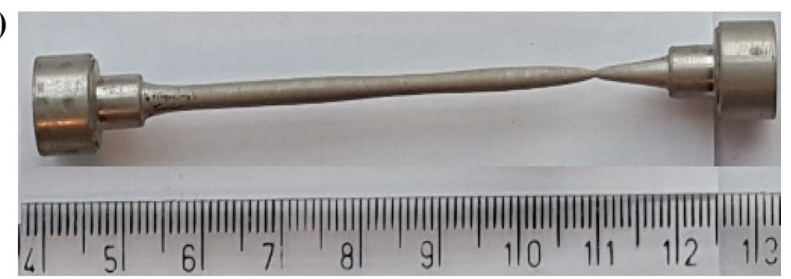

(b)

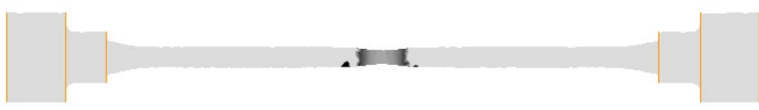

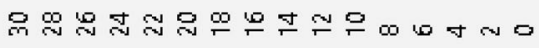

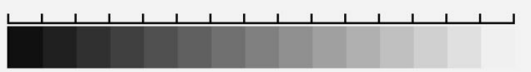

Fig. 11 Experimental (a) and FE simulation (distribution of $K$ ) (b) results of multi-stage stretching of the sample for variant 4

which indicates that the properties of the metal are no longer fully restored during the pause. Obviously, it is impossible to ideally restore material properties after the deformation. For this reason, in the experiment, a neck is finally formed and the sample is destroyed (Fig. 11a). However, in the FE simulation, we can establish the ideal restoration of material properties by zeroing the strain after each stage. In this case, the simulation shows an almost unlimited possible elongation of the sample without a fracture, and hardening at high values of $K$ inhibits the propagation of the neck despite the presence of a stress concentrator, as shown in Fig. 11b.

The elongation strain achieved experimentally in a multistage process substantially depends on the $K$ value in each stage. By the effectiveness of a multi-stage (or multi-pass) process, we mean the ratio of the maximum achievable elongation with a multi-stage deformation to this value obtained by a single-stage process. The dependence of the efficiency achieved in the experiment on the value of $K$ is shown in Fig. 12. Figure 12b-d show the calculations of $K$ for the first stage of stretching for variants $2-4$. From the obtained results, it follows that an increase of $K$ during each stretching stage (3.6, 9.5, and 32 for variants 2,3 and 4, respectively, see Fig. 12b-d) leads to an increase of the effectiveness to 2.2.

\subsection{Experiments in dieless drawing}

The dieless drawing experiments were carried out on equipment the schemes of which are shown in Fig. 4 (DD) and 5 (LDD). Thus, two versions of dieless drawing processes were investigated experimentally (Table 1). One version was a single-pass dieless drawing process with a monotonously increasing difference of velocities $V_{1}-V_{0}$ until the sample was destroyed (see processes DD and LDD in Table 1). The second version was a multi-pass deformation with constant velocities $V_{1}=0.6 \mathrm{~mm} / \mathrm{s}$ and $V_{0}=0.5 \mathrm{~mm} / \mathrm{s}$, which repeated until the fracture happens, see processes multi-pass laser dieless drawing (MLDD) and multi-pass dieless drawing (MDD) in Table 1. The effectiveness of the multi-pass process was estimated as the ratio of the maximum strain in it concerning the strain achieved in a single-pass process. The MLDD processes for $\mathrm{MgCa} 0.8$ and $\mathrm{MgNi} 19$ alloys proved to be the most effective. All MDD processes appeared to be ineffective with effectiveness close to 1.0.

The application of the proposed approach to improve the workability of low plasticity MgNi19 alloy was considered next. Two series of experiments were carried out. In the first case, the deformation was performed in one pass (conventional LDD process). Under this case, the value of $V_{1}-V_{0}$ increased monotonically until the tube was destroyed. In the second case, a multi-pass deformation was performed (the proposed MLDD process) until the tube was destroyed. Figure 13 shows the results obtained for the MgNi19 alloy.

The diameter was measured 5-10 times at a distance of 4-5 $\mathrm{mm}$ from the localization of the fracture in the area with a constant diameter along the length of the pipe. (a)

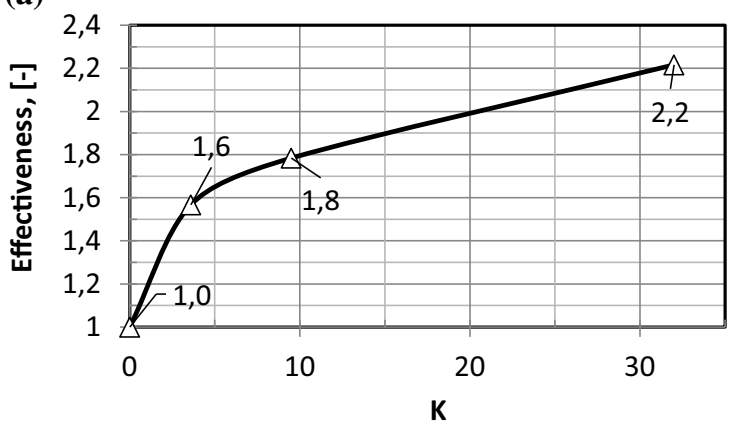

(b)

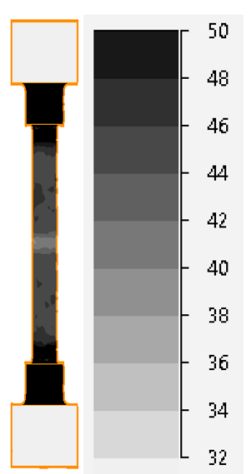

(c)

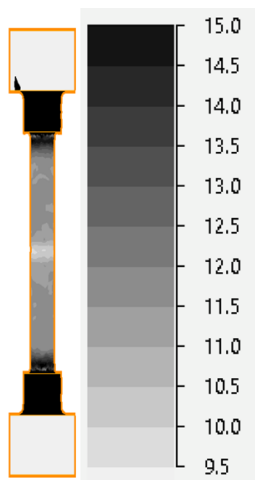

(d)

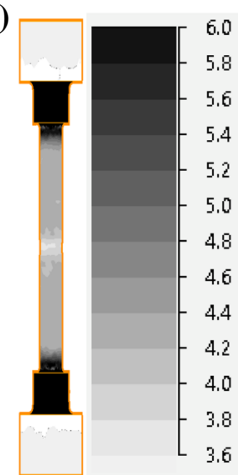

Fig. 12 Dependence of effectiveness of multi-stage deformation on $K(\mathbf{a})$ and FE calculation of $K$ distribution in the sample during the first stage of stretching for variants 2,3 , and 4 (b-d) 
Table 1 Tests conditions and results of experiments

\begin{tabular}{|c|c|c|c|c|c|c|c|c|c|c|}
\hline No. & Material & Process & $V_{1}-V_{0}, \mathrm{~mm} / \mathrm{s}$ & $\begin{array}{l}\text { Number of } \\
\text { passes }\end{array}$ & Strain per pass & $D_{0}, \mathrm{~mm}$ & $d_{\text {final }}, \mathrm{mm}$ & Final strain & $\begin{array}{l}\text { Tempera- } \\
\text { ture, }{ }^{\circ} \mathrm{C}\end{array}$ & Effectiveness \\
\hline 1 & $\mathrm{MgCa} 08$ & MLDD & 0.1 & 7 & 0.14 & 5.5 & 2.0 & 1.01 & 300 & 2.7 \\
\hline 2 & $\mathrm{MgCa} 08$ & LDD & $0.1-0.5$ & 1 & 0.37 & 5.5 & 3.8 & 0.37 & 300 & - \\
\hline 3 & $\mathrm{MgCa} 08$ & MDD & 0.1 & 3 & 0.18 & 5.5 & 3.25 & 0.53 & 300 & 1.04 \\
\hline 4 & $\mathrm{MgCa} 08$ & DD & $0.0-1.5$ & 1 & 0.51 & 5.5 & 3.3 & 0.51 & 300 & - \\
\hline 5 & MgNi19 & MLDD & 0.1 & 5 & 0.11 & 5.5 & 3.1 & 0.57 & 350 & 2.0 \\
\hline 6 & MgNi19 & LDD & $0.1-0.4$ & 1 & 0.29 & 5.5 & 4.1 & 0.29 & 350 & - \\
\hline 7 & $\mathrm{Cu}$ & MDD & 0.2 & 3 & 0.10 & 5.0 & 3.65 & 0.31 & 750 & 0.94 \\
\hline 8 & $\mathrm{Cu}$ & DD & $0-2.5$ & 1 & 0.33 & 5.0 & 3.6 & 0.33 & 750 & - \\
\hline
\end{tabular}

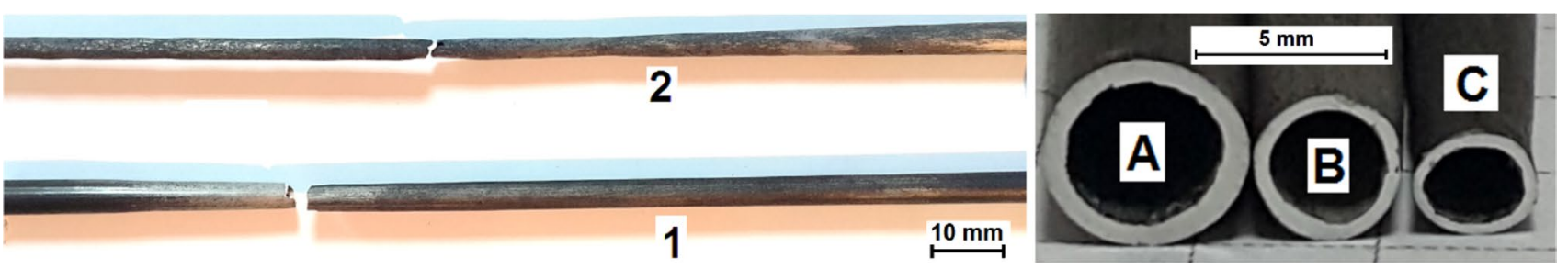

Fig. 13 Tubes from MgNi19 alloy after conventional laser dieless drawing process (1) and proposed process (2); A-initial section of the tube; $\mathrm{B}-$ section before fracture in the conventional LDD process; $\mathrm{C}$ - section before the fracture in the MLDD process

Experiments were repeated $2-3$ times. Strain per pass in Table 1 was calculated based on the measured external tube diameters after each pass of deformation according to the formula

$\varepsilon=\ln \left(\frac{d_{0}}{d_{1}}\right)$,

where $d_{0}$-the external diameter of the tube before pass, $d_{1}$ - the external diameter of the tube after pass For calculation of the final strain in Table $1 d_{0}=D_{0}, d_{1}=d_{\text {final }}$.

\section{Discussion}

To explain the experimental results, the FE simulations of single passes of MDD and MLDD processes were performed. The FE simulation conditions corresponded to one pass in the process (the first row in Table 1 for MLDD and third row in Table 1 for MDD). The results obtained for $\mathrm{MgCa} 0.8$ and MgNi19 alloys are shown in Figs. 14 and 15.

As has been already mentioned, the fundamental difference between the two processes is in the length of the heated zone. The heating zone in the MDD process is several times larger than in the MLDD process. The corresponding calculated temperature distributions are shown in Figs. 14a, d and $15 \mathrm{a}$, d. Numerical simulations showed that the strainrate in the MLDD process is more than five times greater than in the MDD process (Figs. 14b, e, 15b, e). This occurs due to the much shorter deformation zone in MLDD process (elongation in the deformation zone is carried out in a shorter time). The increase in the strain-rate leads to higher values of parameter $K$ in MLDD process (Figs. 14c, 15c) which gives greater stability of the plastic deformation. This is probably the reason for the higher efficiency of the MLDD process.

On the other hand, as follows from Fig. 2, a high strain rate leads to a smaller value of the critical strain and greater values of $D$. As a consequence, the increase in $D$ in one pass is 0.36 for MLDD and 0.325 for MDD, see Fig. 16. This phenomenon is observed when comparing the maximum possible deformations in single-pass DD and LDD processes for the $\mathrm{MgCa} 0.8$ alloy. In the LDD process, the maximum strain value was 0.37 (line 2 in Table 1), whereas this value for the DD process was 0.51 (line 4 in Table 1). Thus, for achieving greater workability in a single pass process, the DD process is more efficient.

This factor, however, in multi-pass processes (MLDD and MDD) is compensated by the restoration of the plastic properties of the material between passes and better deformation stability at large $K$. For this reason, the MLDD process is more efficient than the DD when the conditions described in the paper are applied.

During the dieless drawing of copper, the absence of a substantial hardening zone on the stress-strain curve (Fig. 1e, f) is an additional negative effect on the process stability. In the 
Fig. 14 Results of the simulation of the multi-pass dieless drawing process (MDD) for $\mathrm{MgCa} 0.8$ (a-c) and $\mathrm{MgNi} 19$ (d-f) alloys: a, $\mathbf{d}$ temperature, b, e strain-rate; c, $\mathbf{f}$ parameter $K$ (a)

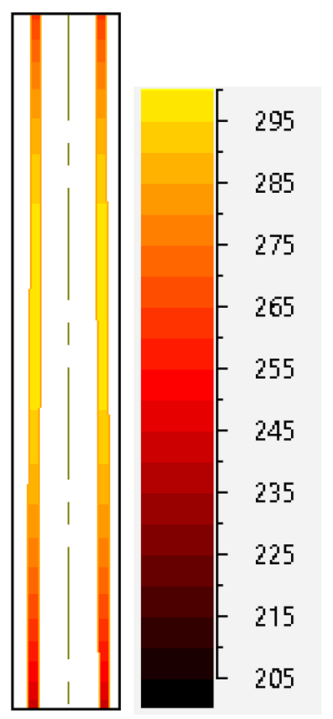

(d)

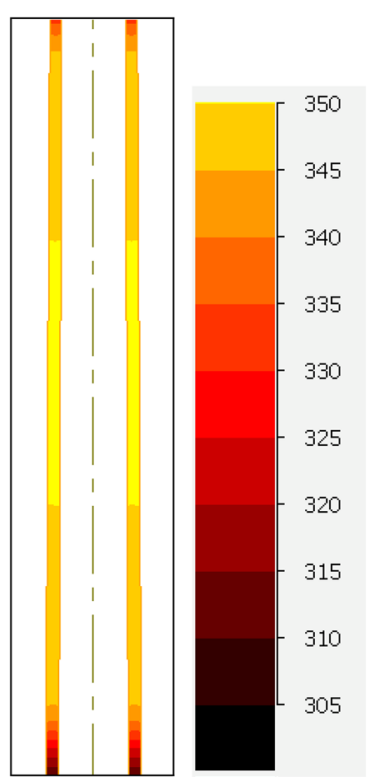

(b)

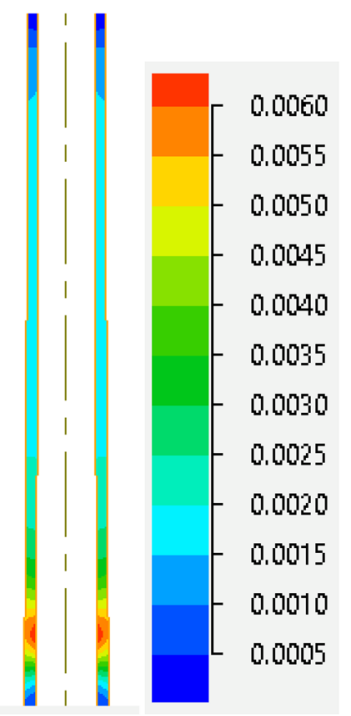

(e)

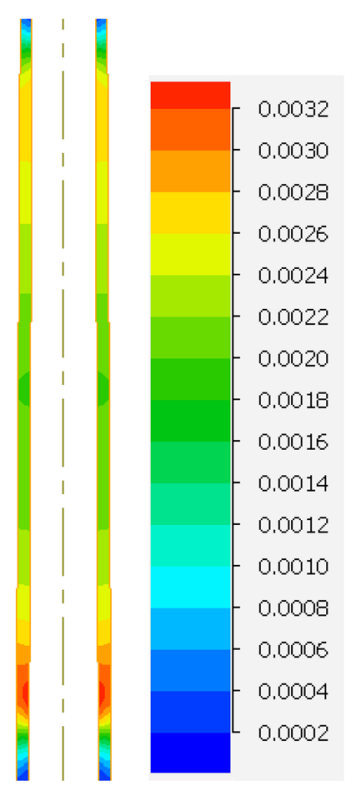

(c)

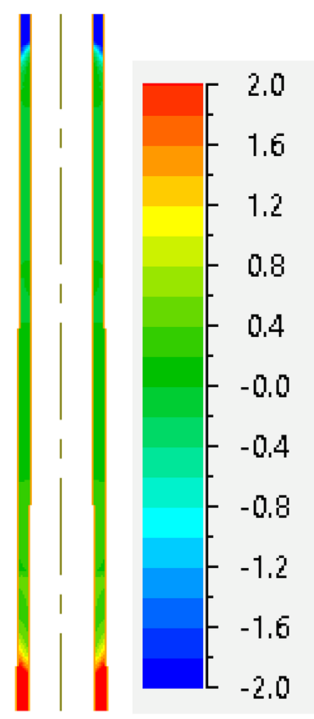

(f)

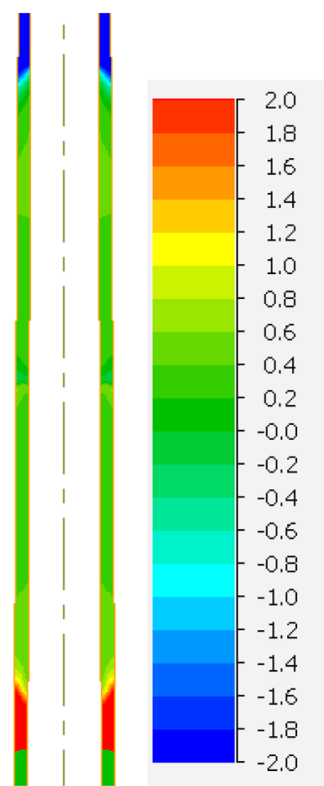

FE simulation (Fig. 17), this is manifested in a wave-like distribution of strain rate (Fig. 17b) and $K$ (Fig. 17c) along the length of the deformation zone, which corresponds to the nonmonotonicity of the curve in Fig. 3c. For these reasons, multipass and single-pass dieless drawing processes of copper have led to the same workability (lines 7 and 8 in Table 1). Thus, the theoretical prognoses and experimental results confirmed the earlier conclusion that copper is material, for which it is more difficult to achieve conditions in which a multi-pass process is more efficient than a single-pass.

\section{Conclusions}

This paper is dedicated to the study of dieless drawing processes with the purpose to improve the workability of processed materials. As a method for improving workability, it is proposed to use the multi-pass dieless drawing. The results indicate that in the multi-pass process of dieless drawing by a rational choice of strain in each pass, it is possible to increase workability (the final strain of 
(a)

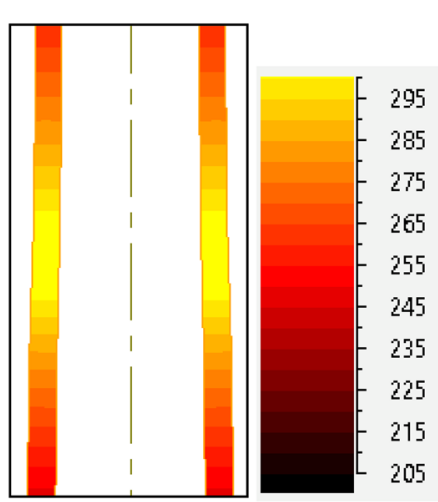

(d)

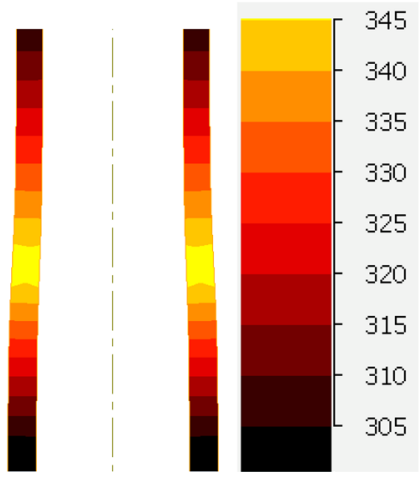

(b)

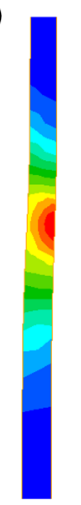

(e)

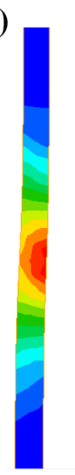

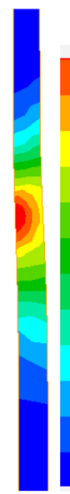

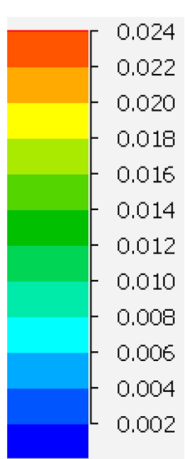

(c)
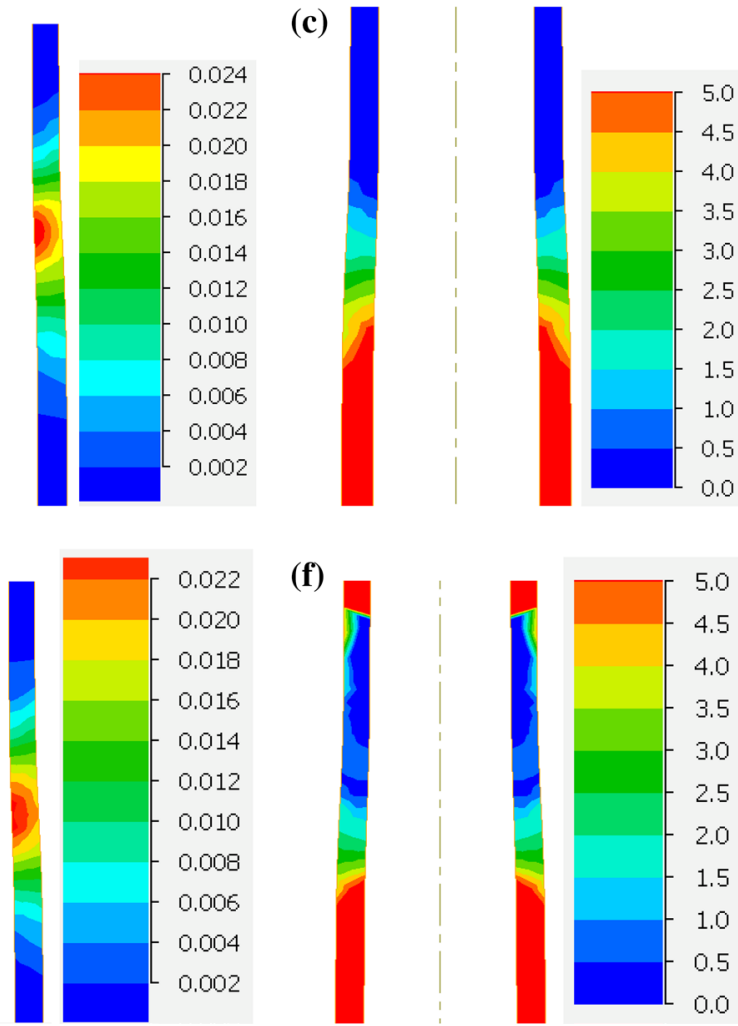

(f)

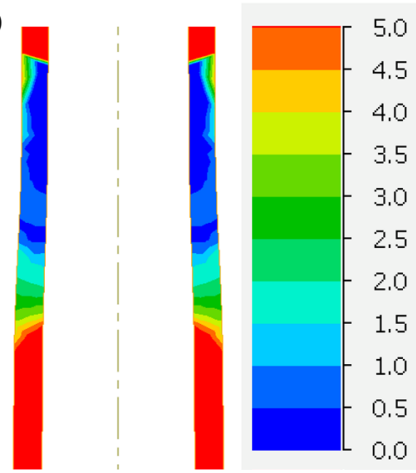

Fig. 15 Results of the simulation of the multi-pass laser dieless drawing process (MLDD) for MgCa0.8 (a-c) and MgNi19 (d-f) alloys: a, d temperature, $\mathbf{b}$, e strain rate; $\mathbf{c}, \mathbf{f}$ parameter $K$

Fig. 16 Results of the simulation of the ductility parameter $D$ for LDD (a) and DD (b) processes for $\mathrm{MgCa} 08$ alloy (a)

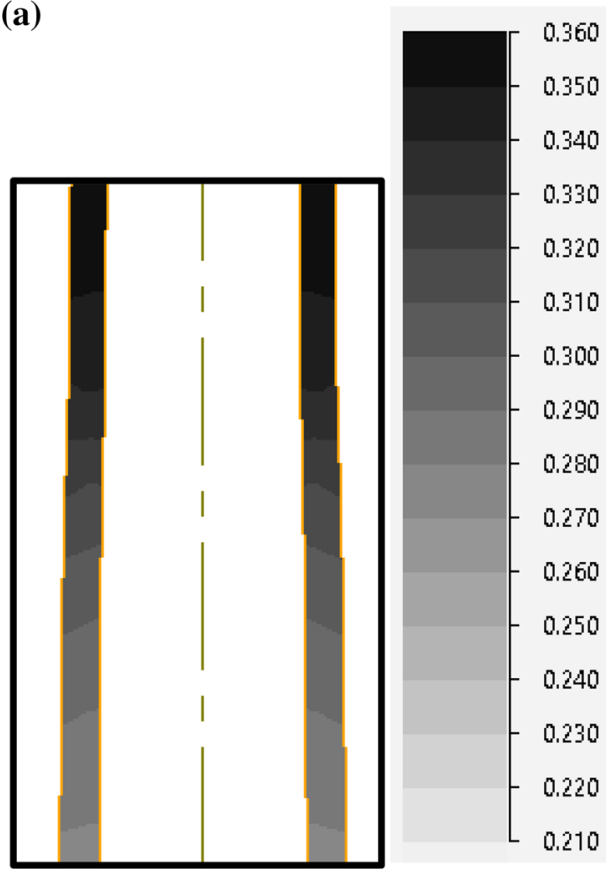

(b)

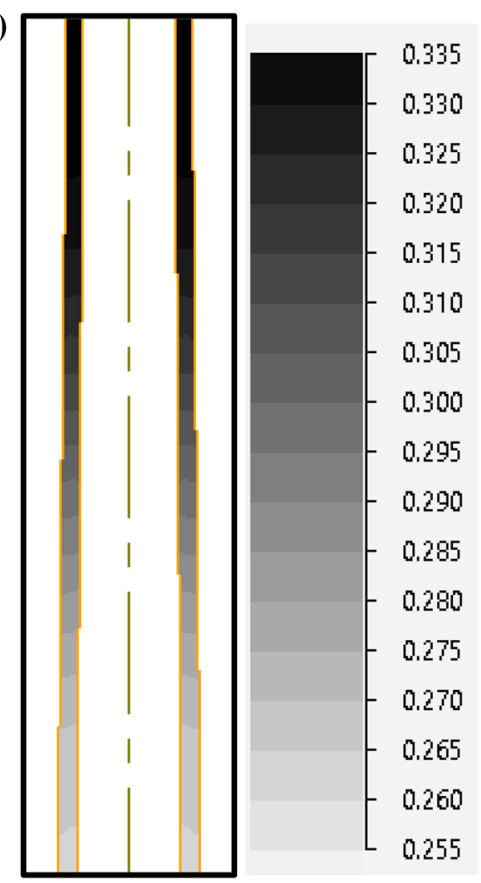

the material to fracture) by more than two times. This is achieved through the application of processing conditions under which the plastic deformation is more stable. Using
FE simulation and experiments it was found that a multipass dieless drawing process with laser heating allowed for more effective increases of workability of the material 
Fig. 17 Results of the simulation of the multi-pass dieless drawing process (MDD) for copper (line 7 in Table 1): a temperature, $\mathbf{b}$ strain rate; $\mathbf{c}$ parameter $K$ (a)

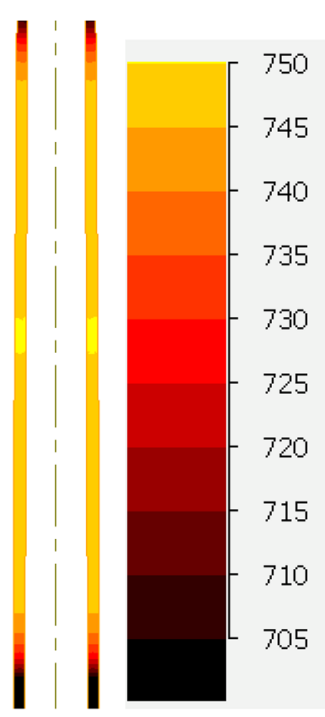

(b)

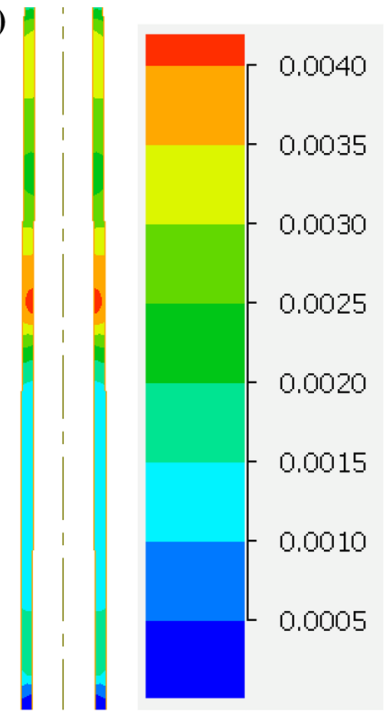

(c)

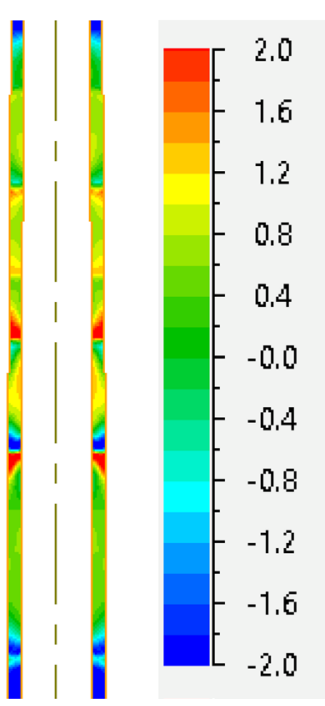

compared to the conventional dieless drawing. The reason for this is the higher strain-rate in the deformation zone in the laser dieless drawing that leads to greater stability of the plastic deformation. This is a previously unknown advantage of laser dieless drawing compared to the conventional dieless drawing process. The proposed method of improving workability shows greater effectiveness for materials with high strain and strain rate sensitivity of the flow stress. From this point of view, the most promising materials were magnesium alloys, the least-pure copper. These results do not rule out the influence of other factors on workability during multi-pass dieless drawing processes, which will require further study. This is especially true for predicting the restoration of mechanical properties between passes.

Funding The work was supported by the NCN of Poland, Project no. 2017/27/B/ST8/01471.

\section{Compliance with ethical standards}

Conflict of interest The authors declare that they have no conflict of interest.

Ethical standards The authors state that ethical standards were not violated when preparing the paper.

Open Access This article is licensed under a Creative Commons Attribution 4.0 International License, which permits use, sharing, adaptation, distribution and reproduction in any medium or format, as long as you give appropriate credit to the original author(s) and the source, provide a link to the Creative Commons licence, and indicate if changes were made. The images or other third party material in this article are included in the article's Creative Commons licence, unless indicated otherwise in a credit line to the material. If material is not included in the article's Creative Commons licence and your intended use is not permitted by statutory regulation or exceeds the permitted use, you will need to obtain permission directly from the copyright holder. To view a copy of this licence, visit http://creativecommons.org/licenses/by/4.0/.

\section{References}

1. Weiss V, Kot RA. Dieless wire drawing with transformation plasticity. Wire J. 1969;9:182-9.

2. Tiernan P, Hillery MT. Dieless wire drawing-an experimental and numerical analysis. J Mater Process Technol. 2004;155-156:1178-83.

3. Furushima T, Shirasaki A, Manabe K. Fabrication of noncircular multicore microtubes by superplastic dieless drawing process. J Mater Process Technol. 2014;214:29-35.

4. Tiernan P, Carolan R, Twohig E, Tofail SAM. Design and development of a novel load-control dieless rod drawing system. CIRP J Manuf Sci Technol. 2011;4:110-7.

5. Li Y, Quick NR, Kar A. Structural evolution and drawability in laser dieless drawing of fine nickel wires. Mater Sci Eng A. 2003;358(1-2):59-70.

6. Supriadi S, Furushima T, Manabe K. Development of precision profile control system with fuzzy model and correction function for tube dieless drawing. J Solid Mech Mater Eng. 2011;5(12):1059-70.

7. Sekiguchi H, Kobatake K, Osakada K. A Fundamental Study on Dieless Drawing, In: Tobias SA, Koenigsberger F, editors. Proceedings of the 15th international machine tool design and research conference. London: Palgrave; 1975. p. 539-544.

8. Furushima T, Manabe K. Experimental and numerical study on deformation behavior in dieless drawing process of superplastic microtubes. J Mater Process Technol. 2007;191:59-63.

9. Furushima T, Manabe K. A novel superplastic dieless drawing process of ceramic tubes. CIRP Ann. 2017;66:265-8.

10. Kustra P, Milenin A, Płonka B, Furushima T. Production process of biocompatible magnesium alloy tubes using extrusion and dieless drawing processes. J Mater Eng Perform. 2016;25(6):2528-35.

11. Milenin A, Kustra P, Du P, Furusawa S, Furushima T. Computer aided design of the laser dieless drawing process of tubes from magnesium alloy with take into account ductility of the material. Procedia Manuf. 2018;15:302-10. 
12. Considère A. Mémoire sur l'emploi du fer et de l'acier dans les constructions. Ann Ponts Chaussees. 1885;9:574-775.

13. He Y, Liu XF, Xie JX, Zhang HG. Processing limit maps for the stable deformation of dieless drawing. Int J Miner Metall Mater. 2011;18(3):330.

14. Milenin A. Rheology-based approach of design the dieless drawing processes. Arch Civ Mech Eng. 2018;18:1309-17.

15. Furushima T, Manabe K. Experimental study on multi-pass dieless drawing process of superplastic $\mathrm{Zn} \% \mathrm{Al} 22$ alloy microtubes. J Mater Process Technol. 2007;187-188:236-40.

16. Crivello JC, Dam B, Denys RV, Dornheim M, Grant DM, Huot J, Jensen TR, de Jongh P, Latroche M, Milanese C, Milčius D, Walker GS, Zlotea CJ, Yartys VA. Review of magnesium hydridebased materials: development and optimisation. Appl Phys A Mater Sci Process. 2016;122:97.

17. Milenin A, Byrska DJ, Grydin O. The multi-scale physical and numerical modeling of fracture phenomena in the $\mathrm{MgCa} 0.8$ alloy. Comput Struct. 2011;89(11-12):1038-49.

18. Garcia V, Cabrera JM, Prado JM. Effects of precipitation during dynamic recrystallization of copper with different oxygen levels. Mater Sci Forum. 2007;558-559:511-6.

19. Rao KP, Suresh K, Prasad YVRK, Dharmendra C, Hort N, Dieringa $\mathrm{H}$. High temperature strength and hot working technology for as-cast Mg-1Zn-1Ca (ZX11) alloy. Metals. 2017;7:405.

20. Doege E, Behrens BA, Kurz G, Vogt O. ASM handbook, metalworking: sheet forming. Form Magnes Alloys. 2006;14B:625-39.

21. Bylya OI, Sarangi MK, Rohit N, Nayak A, Vasin RA, Blackwe PL. Simulation of the material softening during hot metal forming. Arch Metall Mater. 2015;60(3):1887-944.
22. Bylya OI, Khismatullin T, Blackwell P, Vasin RA. The effect of elasto-plastic properties of materials on their formability by flow forming. J Mater Process Technol. 2018;252:34-44.

23. Wright RN, Wright EA. Basic analysis of dieless drawing. Wire J Int. 2000;33:138-43.

24. Slomchak G, Milenin A, Mamuzic I, Vodopivec F. A mathematical model of the formation of the plastic deformation zone in the rolling of rheologically complex metals and alloys. J Mater Process Technol. 1996;58(2):184-8.

25. Biba N, Maximov A, Stebunov S, Vlasov A. The model for simulation of thermally, mechanically and physically coupled problems of metal forming, In: Kusiak J, Majta J, Szeliga D, editors. Proceedings of the 14th international conference on metal forming, Krakow, Poland. 2012. p. 1363-1366.

26. Karjalainen LP, Perttula J. Characteristics of static and metadynamic recrystallization and strain accumulation in hot-deformed austenite as revealed by the stress relaxation method. ISIJ Int. 1996;36:729-36.

Publisher's Note Springer Nature remains neutral with regard to jurisdictional claims in published maps and institutional affiliations. 